\title{
Rocking the dinghy gently
}

What's News? Reclaiming Journalism in New Zealand, edited by Judy McGregor and Margie Comrie. Palmerston North: Dunmore Press, 2002. 284 pp. ISBN 864694164 Whose News?, edited by Margie Comrie and Judy McGregor. Palmerston North: Dunmore Press, 1992. 237 pp. ISBN 0864691572

EW ZEALAND poet C.K.Stead
has always had a keen eye for our sense of national insecurity and inability to indulge in frank debate. New Zealanders, he claims, 'get an agreement, a consensus about where we are and what's right to say about it and anybody who challenges that is not welcome. You don't stand up in the dinghy (Stead, 2000).' So when commentators and academics, in particular, criticise pillars of New Zealand society, there is often a bristling and a stiffening among those pinpointed. Either ignored or angrily dismissed, the criticisms are then left to languish to be unexplored further.

Two people who have made valiant attempts to critique the media in New Zealand have been Massey University academics Judy McGregor and Margie Comrie. Their first foray was Whose News? and now a decade later they have produced What's News? Reclaiming New Zealand Journalism. It is an indictment of New Zealand journalism, media organisations and citizens that the two books are largely singing the same tune.

The editors of Whose News?, released in 1992, aimed to 'contribute to raising the level of debate about the New Zealand news media'(p 9). A concern is that a decade later another volume has appeared, and the editors are still exercised by the low level of 
criticism and debate, which surround the New Zealand news media (pp 711). This paucity of debate is not, of course, unique to journalism and the news media. Nobody wants to rock the national dinghy, it seems, for fear of getting splashed or maybe even falling into the water. Part of the reason for society's antipathy towards robust debate can be put down to our traditional suspicion of things intellectual. So when academics have the temerity to criticise, they get even shorter shrift than other commentators, no matter the worth of their credentials.

The media industry is particularly sensitive to criticism, especially any backed by academic research. Journalists and media organisations are notoriously thinskinned and this despite a media workforce that is better educated, has been introduced to some media theory and understands the basis for much of the criticism. Journalism training in New Zealand, however, is still largely practical and not theoretical. This is what industry tells educators it wants - journalists who have a news sense, are accurate and can spell! Journalism still does not have a strong academic identity in New Zealand. So any New Zealand book that attempts a critique, however mild, is in for a rough sailing.

So back to the two books.

Whose News? has been a valuable handbook for mass communication and journalism classes and for the general reader interested in the New Zealand media. Contributors came from throughout the country, many from a wide range of academic institutions involved in teaching journalism or media studies. There was a good mix of academics, practicing journalists, politicians and media commentators. Topics covered included ownership, politics and the media, ethics and values, and issues in the media such as war, crime and environmental reporting, and the representation of Maori and women in the media.

What's News? has kept largely to this same format and added some new topics such as sports journalism ( $p$ 96), Pacific (p 233) and public journalism ( $\mathrm{p} 259$ ). A surprising omission is the lack of any substantial work on new media and the impact of the internet on journalism. There is more emphasis on academic contributions and from a narrower range of academic institutions. Several of the contributors from the first book appear in the second. Apart from the editors themselves, these include such people as Brian Edwards, Al Morrison and Jim Tully who enlarge on their original contributions.

Whose News? was a welcome addition to the all too few books on the New Zealand media but it is disappointing to see that media critique has not advanced very materially in the 
decade since its publication. Because we lack a journalistic research tradition there is not a lot of empirical research to inform comment. With around 11 journalism schools in the country it would be hoped that more research would be evident.

Take television news as an example. Brian Edwards' 'Cootchie Coo News' was quirkily delineated in the first book (p 15) but did not make use of any current academic research on the topic, notably Joe Atkinson's 'morselisation' study. Edwards' reprise chapter in What's News? (p 16) has not really added anything new to the debate. It might have been better informed if reference had been made to Daniel Cook's doctoral thesis on the topic, Diet News. Maybe these comments are premature, however, because as this is being written, the new head of news and current affairs at Television New Zealand (TVNZ) is promising to reform news and current affairs along the lines of Edwards' and others' critiques.

McGregor can always be relied upon to provide her own meticulous research and her piece on crime news provides a very good jumping off point for anyone studying the influence and effects of crime news in the New Zealand media ( $p$ 81). It is reminiscent of her and Susan Fountaine's excellent studies of media coverage of sportswomen. Which brings us nicely to
John Harvey's chapter on 'new' sports journalism (p 96) and raises the spectre of a personal hobbyhorse - the invisibility of sportswomen. They are as invisible, as are women sports journalists, in his chapter as they are in the news. Nothing much has changed despite McGregor and Fountaine's sterling efforts. So no, Susan Fountaine, 'we are not there yet!' as your chapter asks (p 244). She considers the 'long road to gender equity in the news' and there is still much to be pessimistic about for female journalists (and sportswomen) in New Zealand.

Overall What's News? has tried to steer a middle course between academic research and commentary and does offer the general reader a sound introduction to the various media issues raised. It has rocked the dinghy gently and but not so hard that anybody is likely to fall overboard and get soaked.

\section{Reference}

Stead, C. K. (2000, January 2). Nation's culture on critical list. New Zealand Herald. p C8. 